\title{
Biophysical Characterization and Expression Analysis of Kv1.3 Potassium Channel in Primary Human Leukemic B Cells
}

\author{
Ildiko Szabo ${ }^{a, c}$ Livio Trentin ${ }^{b}$ Valentina Trimarco ${ }^{b}$ Gianpietro Semenzato ${ }^{b}$ \\ Luigi Leanza $^{a}$
}

${ }^{a}$ Department of Biology, University of Padua, ${ }^{b}$ Department of Medicine, Hematology and Immunological Branch and Venetian Institute for Molecular Medicine (VIMM) University of Padua, 'CNR Institute of Neurosciences, University of Padua, Padua, Italy

\section{Key Words}

Potassium channel - Chronic lymphocytic leukemia - B-RAF - Mesenchymal stromal cell • Clofazimine

\begin{abstract}
Background/Aims: Pharmacological inhibition of the potassium channel Kv1.3 has been shown to selectively kill B cells from patients with chronic lymphocytic leukemia (B-CLL). Here we aimed to biophysically characterize and compare Kv1.3 channel activity in B cells isolated either from healthy subjects or patients and investigated the mechanism accounting for the increased protein expression in B-CLL cells. Methods: Kv1.3 activity was measured by patch clamp, while expression of the channel protein was assessed by Western blot and FACS analysis. B-CLL cells were co-cultured with mesenchymal stromal cells (MSC) and Kv1.3 inhibitor-induced apoptosis was assessed. Results: We demonstrate that Kv1.3 is highly expressed and is more active at resting membrane potential in human B-CLL cells than in healthy cells. Channel expression in pathologic cells decreased by the B-RAF kinase inhibitor PLX-4720, while it increased with Doxazosin, an $\alpha 1$-adrenoceptor antagonist. Kv1.3 inhibitors induced death in B-CLL cells also when co-cultured with MSC. Conclusion: Our results contribute to the characterization of B-CLL cells, as it shows that upregulation of Kv1.3 in pathologic $B$ lymphocytes is linked to the oncogenic B-RAF signalling. We also conclude that Kv1.3 inhibitors represent a valuable tool to induce apoptosis of B-CLL cells even in the presence of MSC.
\end{abstract}




\section{Cellular Physiology Cell Physiol Biochem 2015;37:965-978

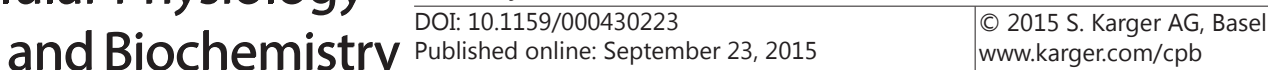 \\ Szabo et al.: Kv1.3 Potassium Channel Expression in B Cells from CLL Patients}

\section{Introduction}

Over the past decade, several experimental evidences linked various ion channels to tumour development and progression e.g. [1,2], indicating that ion channels can be important oncological targets. In addition, since their expression is often altered in cancer cells and depends on progression stages, ion channels are emerging also as cancer biomarkers [3]. Potassium channels are particularly relevant given their regulatory role of cell cycle and of proliferation in various cancer cells $[2,4,5]$. In addition, a correlation was found between $\mathrm{K}^{+}$channel expression and sensitivity of various cancer cells to apoptotic stimuli [6]. Beside plasma membrane-located channels and transporters, intracellular ion channels have been identified as promising oncological targets as well [7, 8].

Different leukemic cells or cell lines, both myeloid and lymphoid, express/overexpress several potassium channels including shaker type voltage-gated Kv1.1, Kv1.3, Kv1.5, Kv11.1, and calcium-activated KCa3.1 $[6,9,10]$. However, detailed biophysical characterization and determination of factors driving high expression of Kv1.3 in primary leukemic cells has not been carried out so far. It has to be pointed out however that malignant B-CLL cells are likely to derive from stem cells or precursors rather than from mature peripheral cells. Thus, the appropriate cell population for a quantitative comparison between B-CLL and healthy cells would be the former one, where $\mathrm{K}^{+}$channel expression was not studied. However, the scope of the present study was to compare the expression between tumor cells and peripheral $\mathrm{B}$ lymphocytes to define the molecular mechanisms that mediate the sensitivity of the tumor cells to Kv1.3 inhibitors and the resistance of normal cells to these inhibitors.

Kv1.3 is expressed in the plasma membrane of various cells but was found to be active also in the mitochondrial inner membrane in several cell types. Three membrane permeant specific Kv1.3 inhibitors, Psora-4, PAP-1 and clofazimine were able to specifically eliminate melanoma cancer cells in vitro and in vivo, while plasma membrane (PM)-located targeting Kv1.3 inhibitor MgTx, Chtx and Shk did not [11,12]. The same drugs efficiently induced apoptosis in isolated primary B-CLL cells, where the channel is present also in the mitochondria. This pathology is characterized by a clonal accumulation of mature apoptosisresistant neoplastic B cells and unfortunately therapeutic options are not resolvent and are limited. We observed that the three drugs killed B-CLL cells but not the residual Tymphocytes of the same patients, even when anti-apoptotic Bcl-2 was overexpressed and the tumor suppressor p53 was mutated [12]. However, the ability of these drugs to overcome bone marrow mesenchymal stromal cell (MSC)-induced chemoresistance has not been studied so far. As previously reported [13], MSC protects leukemia cells from apoptosis induced by chemotherapeutic drugs.

Thus, especially in light of the fact that clofazimine, a rhiminophenazine, is already used in clinic to treat leprosy and some autoimmune disease [14], it is worthwhile to investigate the properties of Kv1.3 in B-CLL cells and the effect of Kv1.3 inhibitors in cells co-cultured with MSC. Biophysical characterization and determination of factors that might drive high expression of Kv1.3 channel in B-CLL cells is also of interest since it may lead to the development of new pharmacological strategies for cancer therapy. Therefore, in the present study we investigated the eventual role of pathways previously shown to regulate potassium channel expression in other systems.

\section{Materials and Methods}

\section{Cell cultures and Reagents}

Jurkat T-cells were cultured at $37^{\circ} \mathrm{C}$ and with $5 \%$ of $\mathrm{CO}_{2}$ in RPMI supplemented with $10 \%$ of Fetal Bovine Serum (FBS). For the experiments, 30,000 Jurkat cells were seeded in a 24 well plate in $1 \mathrm{ml}$ of RPMI with $10 \%$ FBS and treated with the indicated drugs for either 6 days. After treatment, cells were analysed as reported in the following paragraphs. B cells were obtained either from CLL patients or healthy subjects as described below. Written informed consents were obtained from all patients, prior to sample 


\section{Cellular Physiology Cell Physiol Biochem 2015;37:965-978 \begin{tabular}{l|l} 
and Biochemistry Published online: September 23, 2015 & $\begin{array}{l}\text { DO 2015 S. Karger AG, Basel } \\
\text { www.karger.com/cpb }\end{array}$ \\
\hline
\end{tabular} \\ Szabo et al.: Kv1.3 Potassium Channel Expression in B Cells from CLL Patients}

collection, according to the Declaration of Helsinki. The ethic approval for our study was obtained from the local ethic committee of "Regione Veneto on chronic lymphocytic leukemia". Clofazimine and Doxazosin were purchased by Sigma Aldrich (Italy). PLX-4720 was from Selleckchem (USA). Igmesine was obtained from Tocris Bioscience (UK).

\section{$B$ cell isolation}

We obtained peripheral blood from 9 untreated patients with B-CLL as confirmed by clinical, pathologic, and flow cytometric criteria (positive for CD5). Peripheral blood mononuclear cells (PBMCs) from the patients were isolated by density-gradient centrifugation using the Ficoll-Hypaque technique (Amersham Biosciences; Buckinghamshire, UK). The samples were checked for purity by FACS, and the purification procedure was repeated if the percentage of cells other than CD19+ B cells exceeded 5\%. Nonmanipulated peripheral blood B cells were isolated from the PBMCs of healthy donors by negative selection using the RosetteSep isolation kit for B cells (STEMCELL Technologies; Vancouver, Canada).

Mesenchymal stromal cell long-term cultures

Mesenchymal stromal cells (MSCs) were isolated from iliac crest bone marrow (BM) aspirate of B-CLL patients under local anesthesia and diluted 1:3 in Phosphate Buffered Saline (PBS1X) (Euroclone; Milan, Italy) [15]. BM mononuclear cells (BMMCs) were isolated by $\mathrm{F} / \mathrm{H}$ (Amersham Biosciences) centrifugation and plated at density 1,000 cells $/ \mathrm{cm}^{2}$ in Dulbecco's modified Eagle's medium (DMEM) (Euroclone) with $1,000 \mathrm{mg} / \mathrm{ml}$ glucose, L-glutamine, $10 \%$ heated inactivated FBS and $100 \mathrm{U} / \mathrm{ml}$ Penicillin, $100 \mu \mathrm{g} / \mathrm{ml}$ Streptomicin (Life Technologies; Paisley, UK). BMMC suspensions were incubated at $37^{\circ} \mathrm{C}$ in humidified atmosphere containing $5 \% \mathrm{CO}_{2}$ and allowed to attach for 7 days; at this time-point, non-adherent fraction was discarded and adherent cells were fed every week with fresh medium. These cells were maintained until confluence, then they were removed by Accutase (Sigma-Aldrich; Milan, Italy), centrifuged and diluted 1:3 for subsequent expansion in $25 \mathrm{~cm}^{3}$ flasks or cryopreserved for future uses.

$2 \times 10^{6}$ purified human primary B-CLL cells and healthy B cells were seeded on a MSC layer and treated with Doxazosin or PLX-4720 or Igmesine for 6 days as reported. Following, the cells were analysed as stated in the other paragraphs.

\section{Electrophysiology}

Whole-cell currents were recorded with an EPC-7 amplifier (List, Darmstadt, Germany; filter, $1 \mathrm{kHz}$; sampling rate, $5 \mathrm{kHz}$ ) on B cells obtained as described above and cultured in RPMI. Leak currents were not subtracted. The bath solution was composed of $150 \mathrm{mM} \mathrm{NaCl}, 5 \mathrm{mM} \mathrm{KCl}, 2.5 \mathrm{mM} \mathrm{CaCl}, 1 \mathrm{mM} \mathrm{MgCl}{ }_{2}$, and $10 \mathrm{mM}$ HEPES (pH 7.3). The intracellular solution contained $134 \mathrm{mM} \mathrm{KCl}, 1 \mathrm{mM} \mathrm{CaCl} 2,2 \mathrm{mM} \mathrm{MgCl}, 10 \mathrm{mM}$ EGTA, and 10 mM HEPES (pH 7.3). Intracellular voltages are reported, and outward currents are plotted upward.

\section{Kv1.3 detection by FACS}

$1 \times 10^{6}$ cells, either human primary B cells or Jurkat, were incubated in $50 \mu \mathrm{L}$ of DMEM without phenol red and FBS with $1 \mu \mathrm{G}$ of FITC-labelled anti-Kv1.3 antibody (P4247; Sigma Aldrich) for 45 min at $4^{\circ} \mathrm{C}$ in the dark. After incubation, samples were diluted with $300 \mu \mathrm{L}$ of DMEM without phenol red and FBS and analysed by a FACSanto II (BD Biosciences) using the BD Vista software.

\section{Western blotting}

Membrane enriched fraction proteins from Jurkat cells were obtained as previously reported [6]. Briefly, cells were washed in PBS and then resuspended in $300 \mu \mathrm{L}$ of TES buffer (100 mM TES + 1 M sucrose, $100 \mathrm{mM}$ EGTA, 1X cocktail protease inhibitors) and lysed by an electronic pestle (Kontes, Sigma Aldrich) for $2 \mathrm{~min}$ on ice. Unbroken cells were separated by centrifugation at $500 \mathrm{~g}$ for $10 \mathrm{~min}$ at $4^{\circ} \mathrm{C}$. The soluble cytosolic fraction was separated from the membrane-enriched fraction by centrifugation at 19,000 $\mathrm{g}$ for 10 $\min$ at $4^{\circ} \mathrm{C}$.

The pelleted membranes were suspended in TES buffer and separated by SDS-PAGE in a $10 \%$ polyacrylamide gel containing $6 \mathrm{M}$ Urea. To enhance protein separation, samples were solubilized for $1 \mathrm{~h}$ at RT in Sample Buffer (30\% Glycerol + 125 mM Tris/HCl pH 6.8 + 9\% SDS + 0.1 M DTT+ Bromophenol blue). Protein concentration was determined using the BCA method in a 96 well plate $(200 \mu \mathrm{L}$ total volume for 


\section{Cellular Physiology Cell Physiol Biochem 2015;37:965-978 \\ \begin{tabular}{l|l|l}
\hline DOI: 10.1159/000430223 & (C) 2015 S. Karger AG, Basel
\end{tabular}

Szabo et al.: Kv1.3 Potassium Channel Expression in B Cells from CLL Patients

each well) incubating at $37^{\circ} \mathrm{C}$ in the dark for $30 \mathrm{~min}$. Absorbance at $540 \mathrm{~nm}$ was measured by a Packard Spectra Count 96 well plate reader.

After separation by electrophoresis, gels were blotted overnight at $4^{\circ} \mathrm{C}$ onto Polyvinylidene fluoride (PVDF) membranes. After blocking with a $10 \%$ solution of defatted milk, the membranes were incubated with the following primary antibodies overnight at $4^{\circ} \mathrm{C}$ : anti-Kv1.3 (rabbit polyclonal, Alamone Labs APC101); anti-GAPDH (mouse monoclonal, Millipore MAB374). After washing off the excess primary antibody, the membranes were developed using corresponding anti-mouse or anti-rabbit secondary antibodies (Calbiochem). Antibody signal was detected with enhanced chemiluminescence substrate (SuperSignal West Pico Chemiluminescent Substrate, Thermo Scientific). Densitometry was performed using the Quantity One 1-D software (BioRad).

\section{Cell death detection and double staining}

After treatment with clofazimine (1 or $5 \mu \mathrm{M})$, jurkat apoptotic cells were identified by labelling with FITC-Annexin $\mathrm{V}$ at $37^{\circ} \mathrm{C}$ as previously described [11]. Cells were then collected in tubes and analysed by FACS (FACS Canto II BD BioSciences) using the BD Vista software.

\section{Results}

Biophysical and pharmacological characterization of Kv1.3 activity in B-CLL cells and in primary $B$ cells from healthy subjects

Kv1.3, which is crucial for proliferation of lymphocytes [16], may confer a survival advantage on highly proliferating B-CLL cancer cells. A slightly higher expression of Kv1.3 mRNA was observed in pathological B cells compared to the healthy ones [17]. In addition, high level of Kv1.3 was detected in B-CLL cells upon stimulation with activated T4 cells for 3 days [9]. We have previously shown that B cells from CLL patients show higher Kv1.3 protein expression than B cells from healthy subjects: healthy B cells, defined as single-positive CD19 cells, or pathologic B cells, defined as double-positive CD19/CD5 cells, were purified from peripheral blood lymphocytes and subjected to Western blot and FACS analysis revealing higher Kv1.3 expression in the pathologic cells [12].

Here we performed a detailed biophysical characterization of Kv.1.3 in B-CLL cells by patch clamp experiments, because no published reports included such analysis on B-CLL cells. Figure 1A shows representative Kv1.3 currents recorded from healthy and pathologic B cells, while Figure $1 \mathrm{~B}$ reports the peak current measured at $+70 \mathrm{mV}$, which was significantly higher in the B-CLL cells than in control B cells. The relatively low Kv1.3 activity observed in healthy naïve B cells is in accordance with previous reports $[18,19]$, given that increased Kv1.3 activity was observed only in LPS or anti- $\mu$-activated [19] or in class-switched memory B cells [20]. Potassium currents in B-CLL cells exhibited use-dependent inactivation (Fig. 1C), a characteristic property of Kv1.3. We asked whether the higher peak current observed at $+70 \mathrm{mV}$ could have been due to a left shift in the voltage dependence. The current-voltage relationship however is compatible with that observed in healthy B cells (Fig. 1D). The channel was sensitive to Shk, a membrane-impermeant specific inhibitor, and to clofazimine (Fig. 1E) proving that Kv1.3 was giving rise to the observed activity. Finally, we determined if co-culturing with MSC triggers any change in channel activity. To this end, B-CLL cells were cultured on an MSC monolayer for 1 or for 6 days and the whole-cell peak current was measured (Fig. 1F), revealing that after 6 days a slight decrease occurred in B-CLL cells, while the current remained comparable in the case of healthy B cells.

The larger observed current in the B-CLL cells with respect to healthy B cells might be due to an increased single channel conductance and/or to an increased open probability of the channel. Figure 2A shows single channel current-voltage relationships obtained from outside-out patches revealing no significant difference in the conductance values. Next, we performed single channel recordings in the cell-attached configuration and determined channel activity at resting potential $\left(\mathrm{V}_{\text {pip }}=0\right)$. The channel activity was compatible with that previously described for Kv1.3 in the same configuration in Jurkat lymphocytes [21, 22]. Representative current traces of Figure $2 \mathrm{~B}$ and $\mathrm{C}$ illustrate that channel was more active in B-CLL 
Fig. 1. Biophysical and pharmacological characteristics of whole-cell Kv1.3 currents in B-CLL cells. A) Representative whole-cell currents elicited by application of voltage pulses ranging from -90 to $+90 \mathrm{mV}$ in $20 \mathrm{mV}$ steps at 45 -sec intervals, from a holding potential of $-50 \mathrm{mV}$. B) Mean whole-cell peak current \pm SEM recorded at $+70 \mathrm{mV}$ in $65 \mathrm{~B}$-CLL cells obtained from 22 patients and in 27 healthy B cells obtained from 8 healthy subjects. The difference is statistically significant ( $\left.\left.p=6.3 \times 10^{-5}\right) . \mathrm{C}\right)$ Cumulative inactivation, typical of Kv1.3 current, was seen when depolarizing pulses to $+70 \mathrm{mV}$ from $-50 \mathrm{mV}$ holding potential were applied at 1-sec intervals. D) Normalized whole-cell current in function of voltage (mean \pm SD are shown, $\mathrm{n}=5$ for B-CLL nd $\mathrm{n}$ $=4$ for healthy $\mathrm{B}$ cells). E) BCLL Kv1.3 current is inhibited when ShK (30 nM) or clofazimine $(2 \mu \mathrm{M})$ is added to the bath. F) Mean whole cell peak current at $+70 \mathrm{mV}$ in B-CLL or healthy B cells co-cultured with MSC for 1 or 6 days, respectively ( $\mathrm{n}=5$ for each condition). Statistically significant differences $(\mathrm{p}<0.05)$ (with respect to B-CLL cells at 1 day) are marked with asterisk.

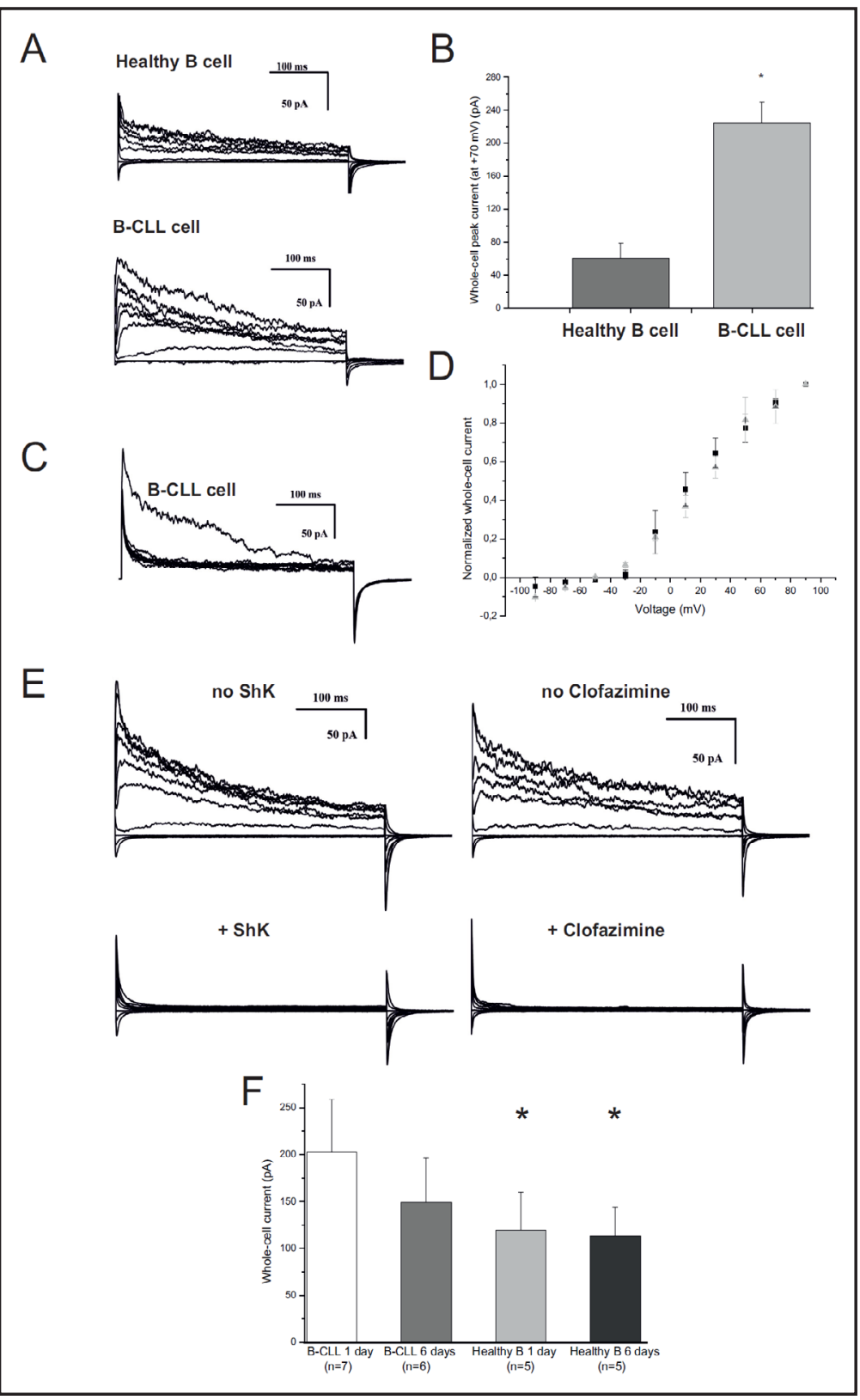

cells. Figure 2D shows representative open probability histograms for healthy and pathologic B cells obtained from $50 \mathrm{sec}$-long current recordings from the experiments shown in Fig 2C.

\section{Inhibition of B-RAF pathway decreases Kv1.3 expression in human leukemic cells}

As demonstrated above, B-CLL cells are characterized by a higher expression of functional Kv1.3 than control B cells. Increased Kv1.3 assembly and activity is consistent with the frequently observed haploinsufficiency of the potassium channel regulating gene (KCNRG) in B-CLL cells, since KCNRG causes the suppression of Kv currents [23]. However, other factors might also play a role in upregulation of potassium channel expression. Therefore, we checked the effect of three compounds, namely Doxazosin, PLX-4720 and Igmesine, which have been shown to alter potassium channel expression at protein level in other systems. Doxazosin is an $\alpha 1$-adrenoceptor antagonist which is able to bind hERG potassium channel (Kv11.1) and to reduce the channel protein level, thereby triggering cell death [24]. B-RAF inhibitor PLX-4720 is a potent anti-proliferative and pro-apoptotic 


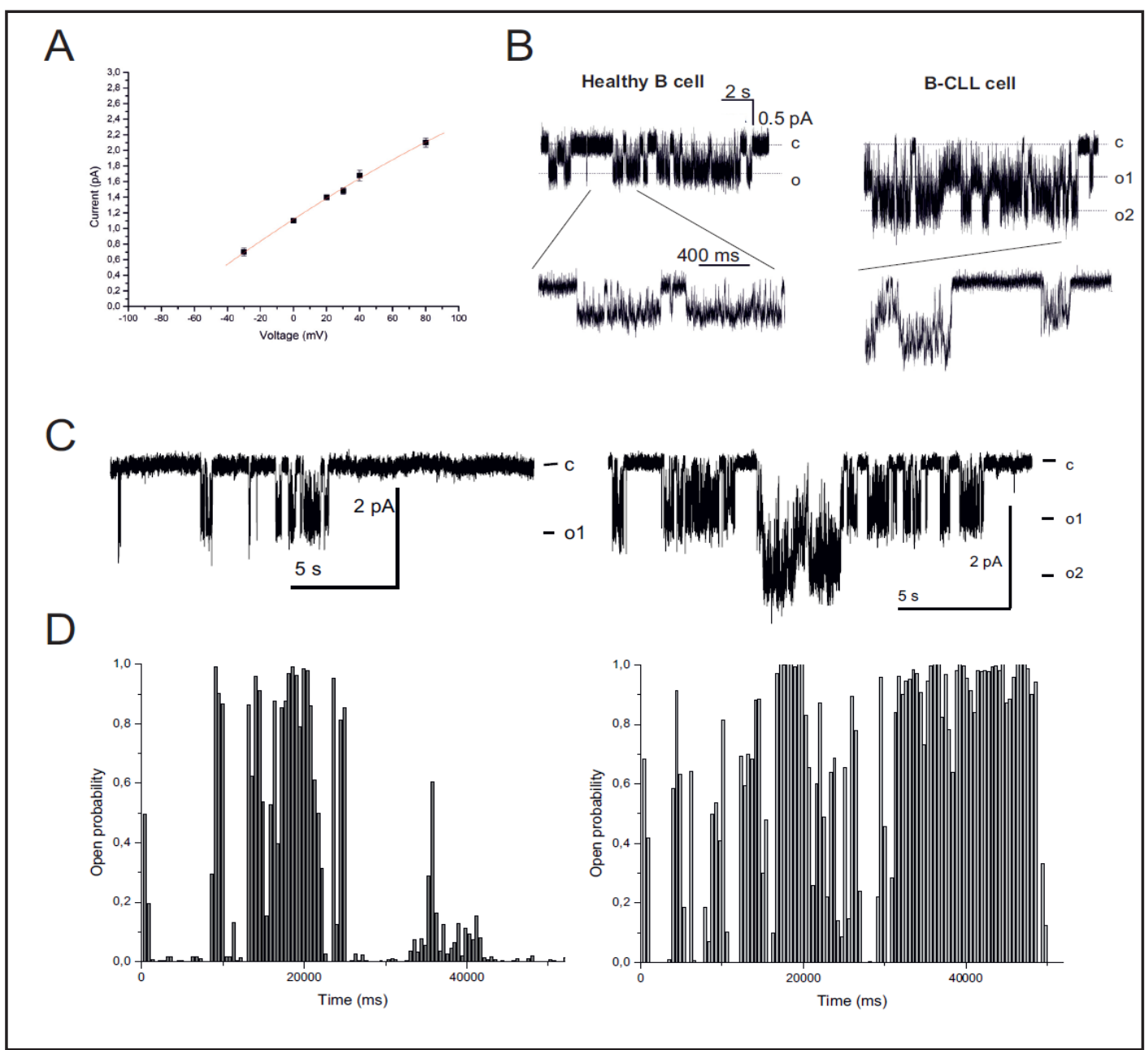

Fig. 2. Kv1.3 activity is higher in B-CLL cells than in B cells at resting potential. A) Single-channel currentvoltage $(I-V)$ relationships were recorded in outside-out patches $(n=5$ patches mean value \pm SEM). Singlechannel conductance is comparable in healthy cells ( $17 \pm 5 \mathrm{pS} ; \mathrm{n}=50$ cells $)$ and B-CLL cells $(21 \pm 3 \mathrm{pS} ; \mathrm{n}=$ 22 cells). B and C) Representative traces from different experiments of single-channel current recorded at $0 \mathrm{mV}$ holding potential in cell-attached configuration using $\mathrm{KCl}$ solution in the pipette and $\mathrm{NaCl}$ solution in the bath. In B) lower traces show channel activity on an expanded time scale. C) Open probability as a function of time was monitored and measured for the indicated times. Open probability histogram was obtained using the PCLAMP8.0 program set.

compound [25] which is able to prevent B-RAF-induced stimulation of hERG by decreasing PM-located channel protein and its activity in rhabdomyosarcoma cells [26]. In addition, a ligand of the Sigma Receptor 1, a known ion channel modulator [27, 28], was tested. This ligand, Igmesine, was shown to decrease Kv channel expression in various cells types [29]. These drugs were used in our experiments at the concentrations described in the above studies.

Primary human B cells, obtained either from CLL patients or healthy subjects were incubated on a MSC cell layer in a medium containing $10 \mu \mathrm{M}$ PLX-4720. After six days, B cells were collected, marked with a FITC labelled anti-Kv1.3 antibody and analyzed by FACS (Fig. 3 and 4A). The results show that inhibition of the B-RAF pathway significantly reduced Kv1.3 protein level in B-CLL cells from patients, but not in healthy cells. Treatment with Doxazosin $(30 \mu \mathrm{M})$ induced a slight up-regulation of Kv1.3 protein expression, again in a more pronounced way in pathologic B-CLL cells with respect to healthy ones. Finally, no effects were observed after incubation with Igmesine $(10 \mu \mathrm{M})$, a Sigma Receptor 1 ligand. 


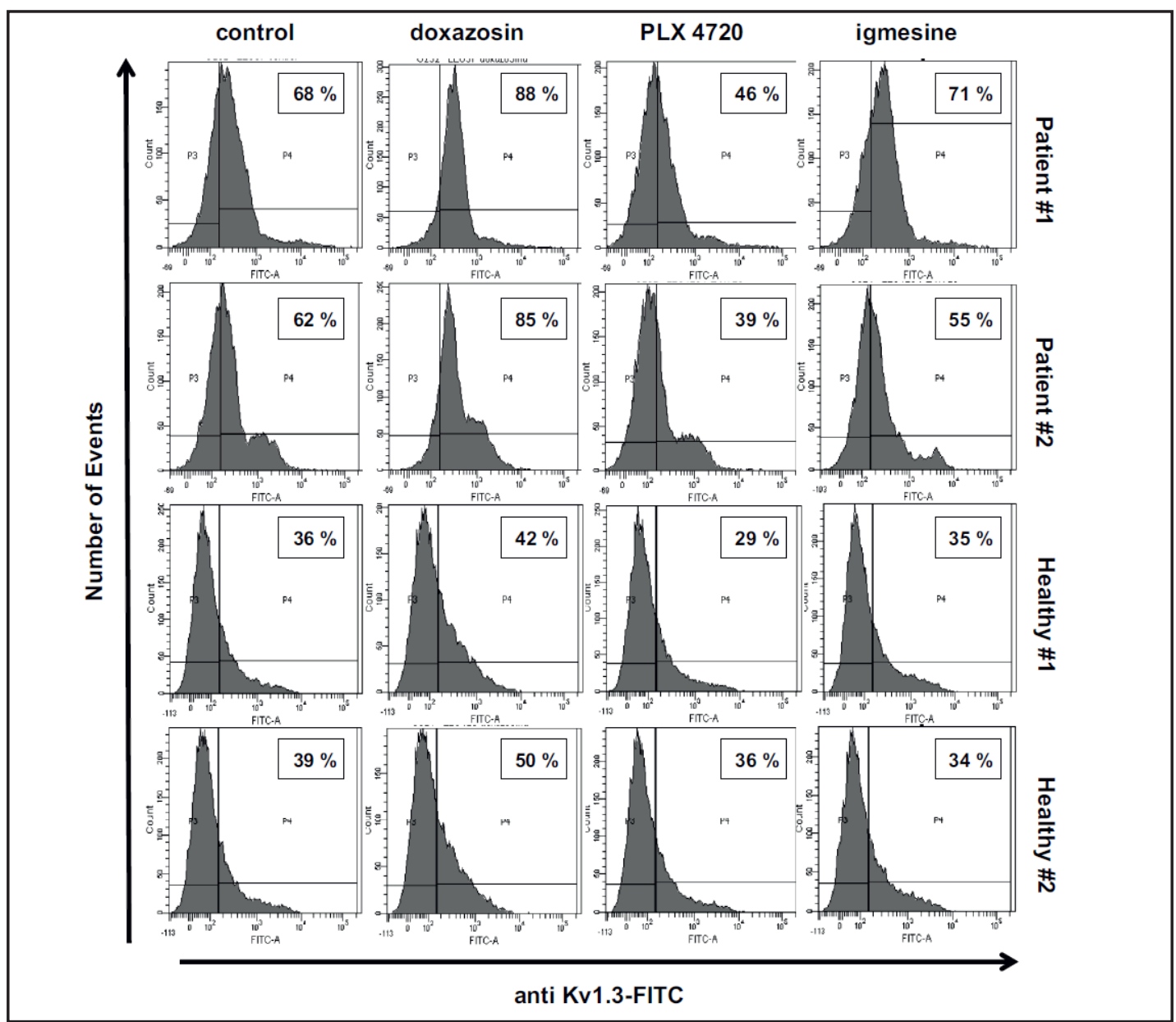

Fig. 3. Kv1.3 protein expression in B-CLL and healthy B cells. B cells either from CLL patients or healthy subjects were seeded on a MSC monolayer and incubated with Doxazosin (30 $\mu \mathrm{M})$, PLX-4720 (10 $\mu \mathrm{M})$ or Igmesine $(10 \mu \mathrm{M})$. After six days, B cells were collected and stained with a FITC labelled anti-Kv1.3 antibody and analysed by FACS. The graphs show a representative experiment with cells from two independent patients and healthy subjects. The values reported are the percentages of Kv1.3 positive cells.

In the case of PLX-4720, where differences were pronounced, we also confirmed by patch clamp analysis that reduction of the PM protein level well correlated with reduction of the whole-cell currents (Fig. 4B-C).

Next, we tested whether our observation can be extended to other type of leukemic cells. Jurkat leukemic $\mathrm{T}$ cells were incubated with the different substances at the indicated concentrations stained with the FITC-anti Kv1.3 antibody and analysed by FACS. After 6 days of incubation similar variations to those found in the primary B-CLL cells were detected (Fig. 5 A-B): PLX-4720 down-regulated Kv1.3 protein expression, while doxazosin upregulated it; again no effects were observed after incubation with the Igmesine. These changes in Kv1.3 protein expression have been demonstrated also by Western Blot, as shown in Figure $5 \mathrm{C}$.

Changes in Kv1.3 expression do not alter leukemic cell sensitivity to Kv1.3 inhibitors

Given the observed differences in Kv1.3 expression following treatment with the above drugs, we verified whether these variations might change the sensitivity of the cells to apoptosis-inducing Kv1.3 inhibitors. Jurkat cells were incubated for 6 days with PLX-4720, Doxazosin and Igmesine and were subsequently treated with either 1 or $5 \mu \mathrm{M}$ clofazimine, previously shown to efficiently kill Jurkat cells (Fig. 5 D). The cells were equally sensitive to 
Fig. 4. Inhibition of B-RAF decreases Kv1.3 expression. A) Quantification of the experiment reported in figure 3 (BCLL cells $n=9$; healthy $B$ cells $\mathrm{n}=4$ ). Values are reported as percentage of Kv1.3 expressing cells +/- S.D. $\left(^{*}=\mathrm{p}<0.05\right.$; $* * *=\mathrm{p}<0.001)$. B) Representative whole-cell (upper panels) and single channel (lower panels) current traces in BCLL cells prior to (left part) and after incubation (right part) with $10 \mu \mathrm{M}$ PLX-4720 for six days in co-culture with MSC.

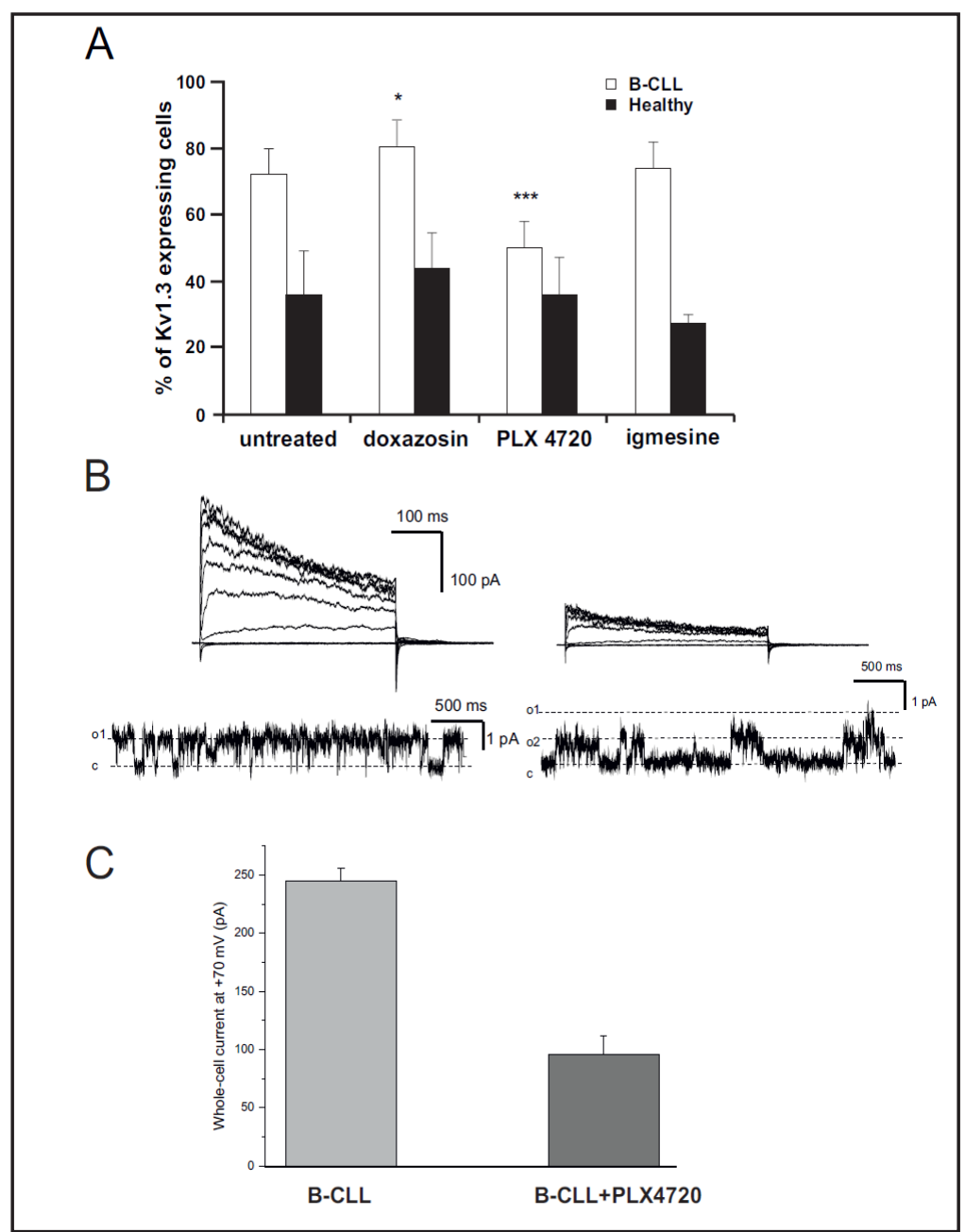

clofazimine treatment with both concentrations, indicating that variation in Kv1.3 expression itself was not sufficient to prevent apoptosis induced by clofazimine.

Kv1.3 inhibitor-induced death of B-CLL cells occurs also in the presence of MSC

As MSC protects leukemia cells from apoptosis induced by chemotherapeutic drugs, we tested the effect of the membrane-permeant Kv1.3 inhibitors in the absence or presence of MSC. Cells were co-cultured with MSC for 6 days and then treated with Psora-4, PAP-1 and clofazimine for 24 hours as previously described [12]. Following, apoptosis was evaluated by Annexin $\mathrm{V}$ binding assay. Figure $6 \mathrm{~A}$. shows that B-CLL cells were sensitive to clofazimine in the presence of MSC, while apoptosis occurred to less extent when the cells were treated with Psora-4 and PAP-1. Thus, we tested whether clofazimine impacts the survival of the MSC cells. Following co-culturing with B-CLL and treatment with clofazimine for 24 hours, MSC cells were washed and stained with Annexin V to reveal apoptotic cells. Treatment with Staurosporin served as positive control. Figure 6B demonstrates that no significant apoptosis of MSC occurred even at the concentration used where the major part of B-CLL were killed.

\section{Discussion}

In the present paper we describe the first detailed electrophysiological characterization of Kv1.3 activity in B-CLL cells from patients as compared to B cells obtained from healthy donors. Furthermore we provide evidence that channel expression is modulated by B-RAF, 
Fig. 5. Modulation of Kv1.3 expression by B-RAF and Doxazosin occurs in leukemic Jurkat $\mathrm{T}$ cells. Effects of Doxazosin $\quad(30$ $\mu \mathrm{M}), \quad$ PLX-4720 $(10 \mu \mathrm{M})$ or Igmesine $(10 \mu \mathrm{M})$ induced on Kv1.3 expression in Jurkat cells. After six days of incubation, cells were stained with a FITC labelled anti- Kv1.3 antibody and analysed by FACS. A) Representative experiment (the reported values are percentage of Kv1.3 positive cells). B) Quantification of Kv1.3 expression in Jurkat cells in different experiment as the one displayed
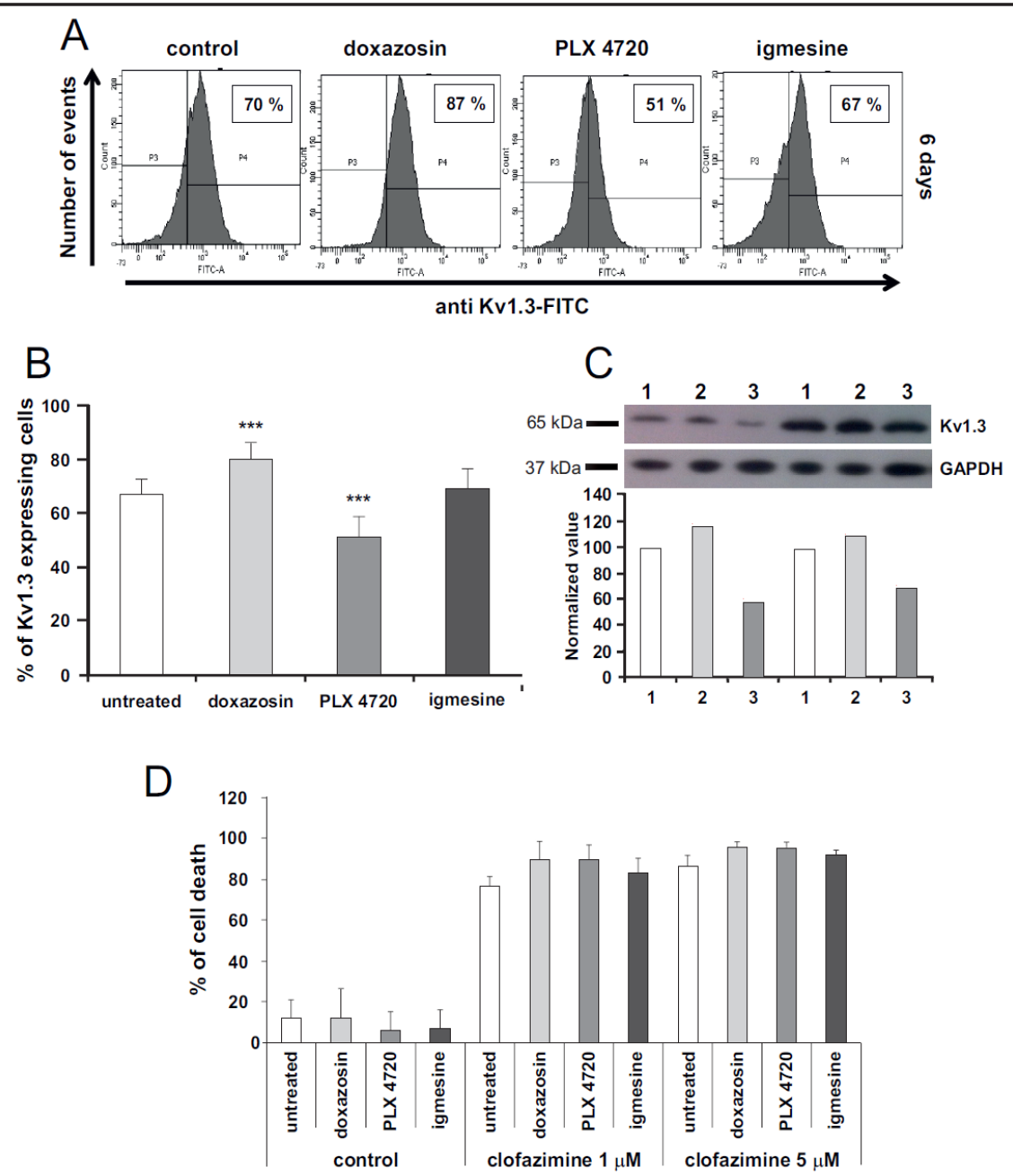

in A (n=9; +/- S.D.; $\left.{ }^{* * *}=\mathrm{p}<0.001\right)$. C) Kv1.3 determination by Western blot in Jurkat cells treated as in A and B in two independent experiments (1: untreated; 2: Doxazosin; 3: PLX-4720). D) Jurkat cells were incubated for six days with Doxazosin $(30 \mu \mathrm{M})$, PLX-4720 $(10 \mu \mathrm{M})$ or Igmesine $(10 \mu \mathrm{M})$. After this period cell death was induced by treatment for $24 \mathrm{~h}$ with the Kv1.3 membrane permeant inhibitor clofazimine as indicated. Apoptotic cells were identified by staining with a FITC labelled Annexin V. Positive cells were determined by FACS. Values are reported as percentage of Annexin V positive cells (apoptotic cells) +/- S.D. $(n=3)$.

especially in the pathologic cells and that sensitivity of these cells to pro-apoptotic Kv1.3 inhibitors is maintained even in the presence of MSC.

The biophysical experiments show that Kv1.3 channels are present and active in both cell types, being however significantly more pronounced in B-CLL than in healthy B cells even at resting potential. We provide evidence that the increased whole-cell current is not due to change in single channel conductance or a shift of the voltage-activation curve, but to an overall increased number of active channels and open probability. Experiments were performed also on B-CLL and healthy B cells cultured on a mesenchymal stromal cells (MSC) monolayer, in order to reproduce the lymph node niche and to let the cells receive different proliferative and anti-apoptotic signals produced by the MSC [30]. Co-culturing with MSC cells partially reduced Kv1.3 activity in B-CLL suggesting that MSC cells release signals of still undefined nature that modulate channel expression and/or activity in the pathologic cells. Adhesion of B-CLLS on MSC is known to favour their survival, proliferation, and tissue retention and a mutual interaction exist between B-CLL and MSC, but not all 
Fig. 6. Clofazimine efficiently kills B-CLL cells but not MSC cells upon co-culturing. B-CLL cells were cultured alone or on MSC monolayer, in order to mimic the lymph node signalling. A) BCLL cells were treated for $24 \mathrm{~h}$ with membrane permeant inhibitors of Kv1.3, Psora-4, PAP-1 or clofazimine, in the presence of cyclosporine $\mathrm{H}$ $(4 \mu \mathrm{M})$ as Multi Drug Resistant pumps blocker (MDRi). Following incubation, B cells were collected and apoptotic cells were determined by staining with a FITC labelled Annexin V by FACS. The values are percentage of dead cells (Annexin-V positive ones $)+/-$ S.D. $(\mathrm{n}=9)$. B) In the same experiments reported in A, MSC cell death was evaluated by fluorescent microscopy after incubation of these cells with an Alexa-568 conjugated Annexin V. The images show a representative experiment. Staurosporin (stauro) was used as positive control $(\mathrm{n}=9)$. Annexin $\mathrm{V}$ signal, due to residual B-CLL cells is visible in some samples.

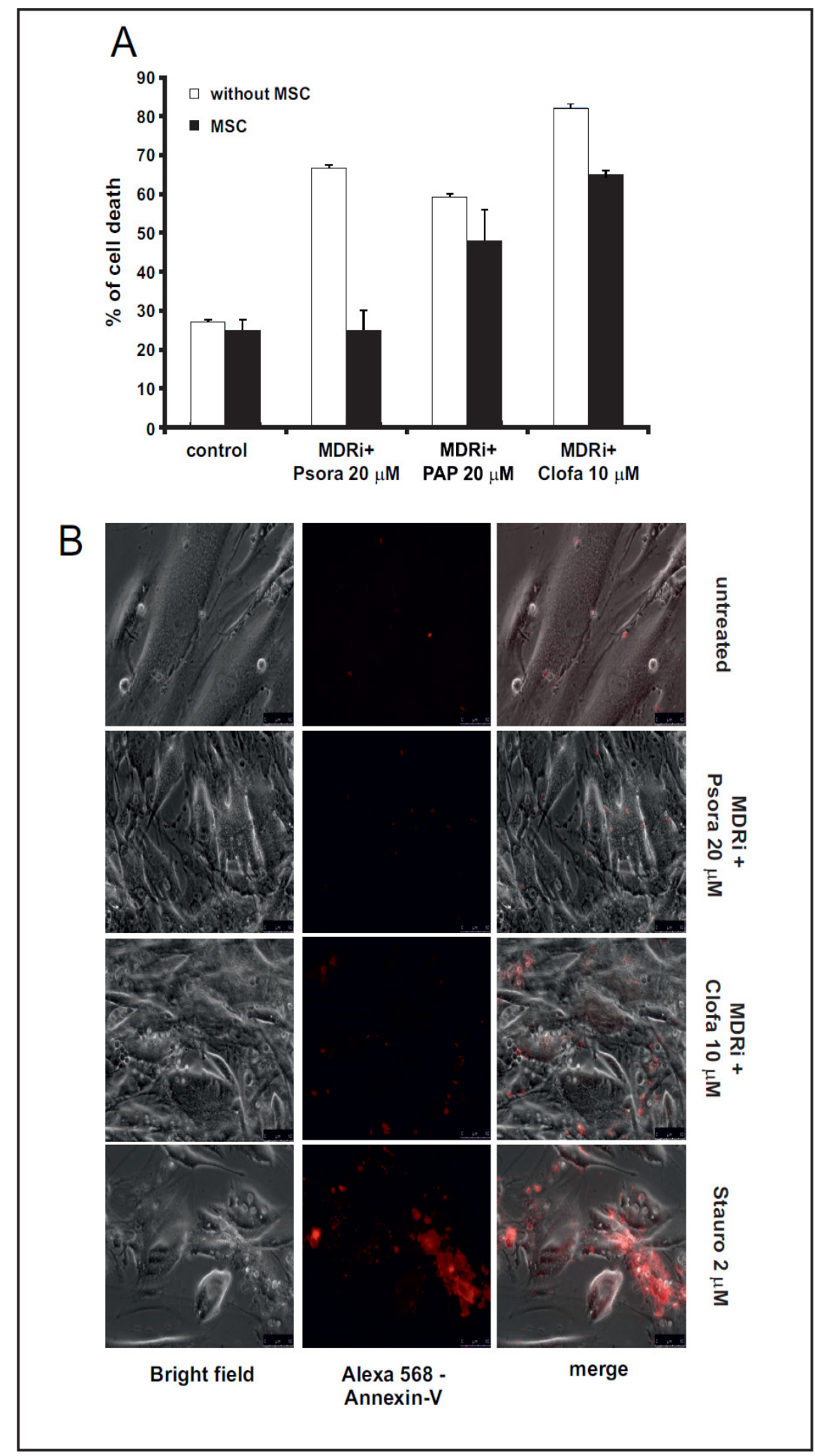

aspects of this interaction have been clarified. However, it is known that activation of the $\mathrm{B}$ cell receptor (BCR) by extracellular ligands is crucial for disease progression in B-CLL and in the interaction between malignant $B$ cells and their microenvironment [30, 31]. This B cells activation pathway is utilized by both normal and neoplastic B cells for survival and expansion. Antigen binding to the BCR induces clustering of BCR components at the cell membrane, along with phosphorylation of some components by activated Src family kinases (Lyn, Blk) e.g. [32]. We have previously shown that in T cells, tyrosine phosphorylation of

\section{KARGER}


Kv1.3 by the Src family kinase p56lck resulted in a decrease of its activity [33]. Whether in the context of the present findings tyrosine phosphorylation by e.g. Lyn occurs and accounts for the decreased channel activity is a still open question, but is beyond the scope of the current manuscript.

Mammalian B-RAF plays an essential role in BCR signaling, belonging to the RAF family of cytosolic kinases that function in the RAS-RAF-MEK-ERK signal transduction or mitogenactivated protein kinase (MAPK) pathway [34]. Several kinases have been shown to be implicated in regulation of potassium channel protein abundance at the level of the PM. For example Janus kinase in the case of calcium-dependent potassium channels [35], mTOR kinase in the case of Kv1.3 and Kv1.5 [36] and the serine/threonine protein kinase B-RAF in the case of HERG [26] impact channel expression. Here we show that B-RAF signalling contributes to the observed increase of Kv1.3 expression in the pathologic B cells. RAF activity has been shown to be essential for B-CLL survival [37]. The RAS/RAF/MEK/ERK pathway is involved in the regulation of cell proliferation, differentiation and survival in response to extracellular signals and is estimated to be deregulated in many malignancies with mutations in the B-RAF gene. Indeed, B-RAF, a key player in the MAPK cascade is a serine/threonine kinase which is mutated in about half of melanomas and at a lower frequency in several other cancers [38], altogether in approximately $7 \%$ of all human cancers. Our results point to a B-RAFmediated up-regulation of Kv1.3 in the pathologic B-CLL cells, which may contribute to the proliferative advantage of these cells. The exact mechanism by which B-RAF affects channel expression has still to be elucidated, since direct phosphorylation can likely be excluded given the time-scale of the observed effect. Interestingly, the neurotrophin B receptor (TrkB) has been shown to impact Kv1.3 surface expression also in a phosphorylation-independent manner [39].

In contrast to B-RAF inhibition, the $\alpha 1$-adrenoceptor antagonist Doxazosin enhanced Kv1.3 expression in B-CLL cells but not in healthy ones. $\alpha 1$-adrenoceptors are highly expressed in human peripheral blood lymphocytes [40] and their activation impact immunological functions [41], however their role in B-CLL has not been elucidated yet. Finally, we tested Igmesine, a Sigma Receptor 1 activator, on the expression of Kv1.3 in B cells. Igmesine at 10 $\mu \mathrm{M}$ concentration has previously been shown to reversibly inhibit voltage-gated outward currents (composed mainly of Kv1.3 current) in Jurkat lymphocytes and three times higher concentration decreased cell growth, without inducing apoptosis [28]. In addition, Sigma Receptor-1 has been shown to physically interact with Kv1.3 when co-expressed in oocytes [42] and to control HERG channel expression through the regulation of subunit trafficking activity in myeloid leukemic cells [43]. Here we show that modulation of Sigma Receptor activity by Igmesine does not alter Kv1.3 expression on long term time scale.

Despite changes in expression of Kv1.3, sensitivity of B-CLL cells toward clofazimine and the other membrane permeant Kv1.3 inhibitors do not vary significantly. We have previously shown in cultured cells that membrane-permeant inhibitors of Kv1.3 induce an increase in the mitochondrial production of reactive oxygen species (ROS). ROS in turn contribute to the detachment and subsequent release of cytochrome $\mathrm{c}$ and other pro-apoptotic factors, leading to apoptosis [44]. Evidence was also obtained pointing to a synergistic effect of mitochondrial Kv1.3 inhibition and of high basal ROS level in leukemic cells which likely accounts for the selective killing of pathologic cells versus healthy B cells [12]. This synergism may explain our findings, i.e. that changes in Kv1.3 expression level alone do not alter the sensitivity of the cells to apoptosis-inducing Kv1.3 inhibitors while a higher basal ROS production in the B-CLL cells is required to be able to pass the critical threshold necessary to selectively kill the pathologic cells by ROS-inducing agents $[45,46]$. The changes in Kv1.3 expression in leukemic cells upon incubation with PLX4720 or by co-culture with MSC are significant but do not lead to complete abolishment of channel expression and activity, therefore the cells remain sensitive to Kv1.3 inhibitors. On the other hand, as Figure 6 illustrates, co-culturing of B-CLL with MSC decrease the ability of the drugs to induce cell death, in accordance with the known anti-apoptotic action of MSC [30]. It is of note that clofazimine, the most promising agent given its excellent safety profile in humans, is able to kill to a significant

\section{KARGER}




\section{Cellular Physiology Cell Physiol Biochem 2015;37:965-978 \begin{tabular}{l|l|l}
\hline DOI: 10.1159/000430223 & (C) 2015 S. Karger AG, Basel
\end{tabular}

extent the pathologic cells even under this condition, but leaves unaffected the healthy MSC cells. Our studies demonstrating selective apoptosis of B-CLL cells by PAP- 1 and Psora-4 has recently been challenged [9]. The authors suggested that differences between the two studies might stem from lack of a supportive microenvironment which activates cell death instead of mitotic programs. Here we show that death with all three membrane-permeant inhibitors occur to B-CLL cells also when the supportive microenvironment is mimicked by MSC. We note instead, that Grossinger and colleagues used lower concentration of PAP-1 and Psora-4 in their studies with respect to the ones used by us. Most importantly, they applied the drugs in the absence of multidrug resistance pump inhibitors, therefore allowing the rapid export of the drugs from the intracellular environment [11] and preventing the effect of the drugs on the mitochondrial channel.

In summary, the present work provides evidence that Kv1.3 expression and activity is upregulated in B-CLL cells with respect to B cells from healthy subject possibly via a B-RAFmediated signalling pathway and identifies clofazimine as a selective, potent apoptosisinduced agent of B-CLL cells even in the presence of mesenchymal stromal cells. The general view is emerging that modulation of ion channel activity in B-CLL cells might be a strategy to pursue for therapeutical purposes [9, 12, 47-49].

\section{Acknowledgements}

The authors are grateful to the funding agencies supporting our work. Italian Association for Cancer Research grant (to I.S. n. 11814, and 15397 to L.T.), a Progetti di Rilevante Interesse Nazionale grant of the Italian Ministry of Education and Research (to I.S. and to L.T.) and a Young Investigator Grant of the University of Padova (GRIC12NN5G) to L.L. were used. We are grateful to Cristina Gattazzo and Federica Frezzato for help with isolation of B cells. This work was supported also by grants of Regione Veneto on chronic lymphocytic leukemia to LT and GS. The funders had no role in study design, data collection and analysis, decision to publish, or preparation of the manuscript.

\section{Disclosure Statement}

The author declare that they have no conflict of interest.

\section{References}

1 Arcangeli A, Crociani O, Lastraioli E, Masi A, Pillozzi S, Becchetti A: Targeting ion channels in cancer: a novel frontier in antineoplastic therapy. Curr Med Chem 2009;16:66-93.

2 Pardo LA, Stuhmer W: The roles of K(+) channels in cancer. Nat Rev Cancer 2014;14:39-48.

3 Lastraioli E, Iorio J, Arcangeli A: Ion channel expression as promising cancer biomarker. Biochim Biophys Acta 2014;pii: S0005-2736(14)00452-0.

4 Urrego D, Tomczak AP, Zahed F, Stuhmer W, Pardo LA: Potassium channels in cell cycle and cell proliferation. Philos Trans R Soc Lond B Biol Sci 2014;369:20130094.

$5 \quad$ Huang X, Jan LY: Targeting potassium channels in cancer. J Cell Biol 2014;206:151-162.

6 Leanza L, O'Reilly P, Doyle A, Venturini E, Zoratti M, Szegezdi E, Szabò I: Correlation between potassium channel expression and sensitivity to drug-induced cell death in tumor cell lines. Curr Pharm Des 2014;20:189-200.

7 Leanza L, Biasutto L, Managò A, Gulbins E, Zoratti M, Szabò I: Intracellular ion channels and cancer. Front Physiol 2013;4:227.

8 Leanza L, Zoratti M, Gulbins E, Szabò I: Mitochondrial ion channels as oncological targets. Oncogene 2014;33:5569-5581. 


\section{Cellular Physiology Cell Physiol Biochem 2015;37:965-978 \begin{tabular}{l|l} 
DOI: 10.1159/000430223 & (C) 2015 S. Karger AG, Basel
\end{tabular}

9 Grossinger EM, Weiss L, Zierler S, Rebhandl S, Krenn PW, Hinterseer E, Schmolzer J, Asslaber D, Hainzl S, Neureiter D, Egle A, Pinon-Hofbauer J, Hartmann TN, Greil R, Kerschbaum HH: Targeting proliferation of chronic lymphocytic leukemia (CLL) cells through KCa3.1 blockade. Leukemia 2014;28:954-958.

10 Arcangeli A, Pillozzi S, Becchetti A: Targeting ion channels in leukemias: a new challenge for treatment. Curr Med Chem 2012;19:683-696.

11 Leanza L, Henry B, Sassi N, Zoratti M, Chandy KG, Gulbins E, Szabò I: Inhibitors of mitochondrial Kv1.3 channels induce Bax/Bak-independent death of cancer cells. EMBO Mol Med 2012;4:577-593.

12 Leanza L, Trentin L, Becker KA, Frezzato F, Zoratti M, Semenzato G, Gulbins E, Szabò I: Clofazimine, Psora-4 and PAP-1, inhibitors of the potassium channel Kv1.3, as a new and selective therapeutic strategy in chronic lymphocytic leukemia. Leukemia 2013;27:1782-1785.

13 Pillozzi S, Masselli M, De Lorenzo E, Accordi B, Cilia E, Crociani O, Amedei A, Veltroni M, D'Amico M, Basso G, Becchetti A, Campana D, Arcangeli A: Chemotherapy resistance in acute lymphoblastic leukemia requires hERG1 channels and is overcome by hERG1 blockers. Blood 2011;117:902-914.

14 Cholo MC, Steel HC, Fourie PB, Germishuizen WA, Anderson R: Clofazimine: current status and future prospects." J Antimicrob Chemother 2012;67:290-298.

15 Frezzato F, Trimarco V, Martini V, Gattazzo C, Ave E, Visentin A, Cabrelle A, Olivieri V, Zambello R, Facco M, Zonta F, Cristiani A, Brunati AM, Moro S, Semenzato G, Trentin L: Leukaemic cells from chronic lymphocytic leukaemia patients undergo apoptosis following microtubule depolymerization and Lyn inhibition by nocodazole. Br J Haematol 2014;165:659-672.

16 Cahalan MD, Chandy KG: The functional network of ion channels in T lymphocytes. Immunol Rev 2009;231:59-87.

17 Smith GA, Tsui HW, Newell EW, Jiang X, Zhu XP, Tsui FW, Schlichter LC: Functional up-regulation of HERG K+ channels in neoplastic hematopoietic cells. J Biol Chem 2002;277:18528-18534.

18 Partiseti M, Choquet D, Diu A, Korn H: Differential regulation of voltage- and calcium-activated potassium channels in human B lymphocytes. J Immunol 1992;148:3361-3368.

19 Partiseti M, Korn H, Choquet D: Pattern of potassium channel expression in proliferating B lymphocytes depends upon the mode of activation. J Immunol 1993;151:2462-2470.

20 Wulff H, Knaus HG, Pennington M, Chandy KG: K+ channel expression during B cell differentiation: implications for immunomodulation and autoimmunity. J Immunol 2004;173:776-786.

21 Pahapill PA, Schlichter LC: Modulation of potassium channels in intact human T lymphocytes. J Physiol 1992;445:407-430.

22 Szabò I, Nilius B, Zhang X, Busch AE, Gulbins E, Suessbrich H, Lang F: Inhibitory effects of oxidants on n-type K+ channels in T lymphocytes and Xenopus oocytes. Pflugers Arch 1997;433:626-632.

23 Birerdinc A, Nohelty E, Marakhonov A, Manyam G, Panov I, Coon S, Nikitin E, Skoblov M, Chandhoke V, Baranova A: Pro-apoptotic and antiproliferative activity of human KCNRG, a putative tumor suppressor in 13q14 region. Tumour Biol 2010;31:33-45.

24 Staudacher I, Jehle J, Staudacher K, Pledl HW, Lemke D, Schweizer PA, Becker R, Katus HA, Thomas D: HERG K+ channel-dependent apoptosis and cell cycle arrest in human glioblastoma cells. PLoS One 2014;9:e88164.

25 Fuchs 0: Targeting of NF-kappaB signaling pathway, other signaling pathways and epigenetics in therapy of multiple myeloma. Cardiovasc Hematol Disord Drug Targets 2013;13:16-34.

26 Pakladok T, Hosseinzadeh Z, Almilaji A, Lebedeva A, Shumilina E, Alesutan I, Lang F: Up-regulation of hERG $\mathrm{K}(+)$ channels by B-RAF. PLoS One 2014;9:e87457.

27 Renaudo A, L'Hoste S, Guizouarn H, Borgese F, Soriani O: Cancer cell cycle modulated by a functional coupling between sigma-1 receptors and Cl- channels. J Biol Chem 2007;282:2259-2267.

28 Renaudo A, Watry V, Chassot AA, Ponzio G, Ehrenfeld J, Soriani O: Inhibition of tumor cell proliferation by sigma ligands is associated with $\mathrm{K}+$ Channel inhibition and p27kip1 accumulation. J Pharmacol Exp Ther 2004;311:1105-1114.

29 Martial S, Giorgelli JL, Renaudo A, Derijard B, Soriani O: SP600125 inhibits Kv channels through a JNKindependent pathway in cancer cells. Biochem Biophys Res Commun 2008;366:944-950.

30 Burger JA, Gribben JG: The microenvironment in chronic lymphocytic leukemia (CLL) and other B cell malignancies: insight into disease biology and new targeted therapies. Semin Cancer Biol 2014;24:71-81.

31 Scupoli MT, Pizzolo G: Signaling pathways activated by the B-cell receptor in chronic lymphocytic leukemia. Expert Rev Hematol 2012;5:341-348. 


\section{Cellular Physiology Cell Physiol Biochem 2015;37:965-978 \begin{tabular}{l|l|l}
\hline DOI: 10.1159/000430223 & (C) 2015 S. Karger AG, Basel
\end{tabular}

32 Zonta F, Pagano MA, Trentin L, Tibaldi E, Frezzato F, Trimarco V, Facco M, Zagotto G, Pavan V, Ribaudo G, Bordin L, Semenzato G, Brunati AM: Lyn sustains oncogenic signaling in chronic lymphocytic leukemia by strengthening SET-mediated inhibition of PP2A. Blood 2015; 125:3747-3755.

33 Szabò I, Gulbins E, Apfel H, Zhang X, Barth P, Busch AE, Schlottmann K, Pongs O, Lang F: Tyrosine phosphorylation-dependent suppression of a voltage-gated $\mathrm{K}+$ channel in T lymphocytes upon Fas stimulation. J Biol Chem 1996;271:20465-20469.

34 Roskoski R Jr: ERK1/2 MAP kinases: structure, function, and regulation. Pharmacol Res 2012;66:105-143.

35 Hosseinzadeh Z, Almilaji A, Honisch S, Pakladok T, Liu G, Bhavsar SK, Ruth P, Shumilina E, Lang F: Upregulation of the large conductance voltage- and Ca2+-activated $\mathrm{K}+$ channels by Janus kinase 2. Am J Physiol Cell Physiol 2014;306:C1041-1049.

36 Tyan L, Sopjani M, Dermaku-Sopjani M, Schmid E, Yang W, Xuan, Shumilina E, Lang F: Inhibition of voltagegated K+ channels in dendritic cells by rapamycin. Am J Physiol Cell Physiol 2010;299:C1379-1385.

37 Fecteau JF, Bharati IS, O'Hayre M, Handel TM, Kipps TJ, Messmer D: Sorafenib-induced apoptosis of chronic lymphocytic leukemia cells is associated with downregulation of RAF and myeloid cell leukemia sequence 1 (Mcl-1). Mol Med 2012;18:19-28.

38 Wellbrock C, Karasarides M, Marais R: The RAF proteins take centre stage. Nat Rev Mol Cell Biol 2004;5:875-885.

39 Colley BS, Biju KC, Visegrady A, Campbell S, Fadool DA: Neurotrophin B receptor kinase increases Kv subfamily member 1.3 (Kv1.3) ion channel half-life and surface expression. Neuroscience 2007;144:531546.

40 Ricci A, Bronzetti E, Conterno A, Greco S, Mulatero P, Schena M, Schiavone D, Tayebati SK, Veglio F, Amenta F: Alpha1-adrenergic receptor subtypes in human peripheral blood lymphocytes. Hypertension 1999;33:708-712.

41 Grisanti LA, Perez DM, Porter JE: Modulation of immune cell function by alpha(1)-adrenergic receptor activation. Curr Top Membr 2011;67:113-138.

42 Kinoshita M, Matsuoka Y, Suzuki T, Mirrielees J, Yang J: Sigma-1 receptor alters the kinetics of Kv1.3 voltage gated potassium channels but not the sensitivity to receptor ligands. Brain Res 2012;1452:1-9.

43 Crottes D, Martial S, Rapetti-Mauss R, Pisani DF, Loriol C, Pellissier B, Martin P, Chevet E, Borgese F, Soriani O: Sig1R protein regulates hERG channel expression through a post-translational mechanism in leukemic cells. J Biol Chem 2011;286:27947-27958.

44 Gulbins E, Sassi N, Grassme H, Zoratti M, Szabò I: Role of Kv1.3 mitochondrial potassium channel in apoptotic signalling in lymphocytes. Biochim Biophys Acta 2010;1797:1251-1259.

45 Trachootham D, Zhang H, Zhang W, Feng L, Du M, Zhou Y, Chen Z, Pelicano H, Plunkett W, Wierda WG, Keating MJ, Huang P: Effective elimination of fludarabine-resistant CLL cells by PEITC through a redoxmediated mechanism. Blood 2008;112:1912-1922.

46 Trachootham D, Alexandre J, Huang P: Targeting cancer cells by ROS-mediated mechanisms: a radical therapeutic approach? Nat Rev Drug Discov 2009;8:579-591.

47 Gasparoli L, D'Amico M, Masselli M, Pillozzi S, Caves R, Khuwaileh R, Tiedke W, Mugridge K, Pratesi A, Mitcheson JS, Basso G, Becchetti A, Arcangeli A: New pyrimido-indole compound CD-160130 preferentially inhibits the KV11.1B isoform and produces antileukemic effects without cardiotoxicity. Mol Pharmacol 2015;87:183-196.

48 Leanza L, Venturini E, Kadow S, Carpinteiro A, Gulbins E, Becker KA: Targeting a mitochondrial potassium channel to fight cancer. Cell Calcium 2015;58:131-138.

49 Pillozzi S, Gasparoli L, Stefanini M, Ristori M, D'Amico M, Alessio E, Scaletti F, Becchetti A, Arcangeli A, Messori L: NAMI-A is highly cytotoxic toward leukaemia cell lines: evidence of inhibition of KCa 3.1 channels. Dalton Trans 2014;43:12150-12155. 